\title{
An introduction to the
}

\section{GDS Regulations in Northern Ireland}

\section{Alan Pitcaithley \\ Practice Management Consultant}

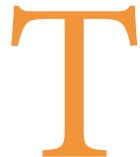

he provision of General Dental Services in Northern Ireland is governed primarily by the Health and Personal Social Services

General Dental Services Regulations (Northern Ireland) 1993 and the various updates and amendments made to these over the years.

Overall policy for General Dental Services in Northern Ireland is set by the Department of Health with the delivery of services managed by the Health and Social Care Board (HSCB). In providing General Dental Services, dentists are independent contractor principals with self-employed status who provide primary care dentistry on behalf of the HSCB.

The HSCBs role includes:

$\rightarrow$ The dental list - maintaining accurate lists of contractor principals and the services they offer

$\rightarrow$ Terms of service - issuing GDS contracts to dentists

$\rightarrow$ Monitoring compliance - through practice inspections

$\rightarrow$ Making payments to dentists - through the Business Services Organisation (BSO).

\section{Maintaining oral health}

Dentists are encouraged to establish ongoing relationships with their patients and are required to provide the care and treatment necessary to secure and maintain oral health. This is defined as:

'...such a standard of health of the teeth, their supporting structures and other tissues of the mouth, and of dental efficiency, as in the case of any patient is reasonable having regard to the need to safeguard his [or her] general health'
HSC patients are entitled to:

$\rightarrow$ Continued access to HSC treatment

$\rightarrow$ Emergency cover

$\rightarrow$ Written treatment plans and, where necessary, an estimate of the costs

$\rightarrow$ Free replacement of certain restorations which fail within a year, and

$\rightarrow$ In most circumstances, three months' written notice of withdrawal of this service.

\section{The dental list}

In order to provide GDS services a dentist must be on the HSCB's dental list. The dental list provides information on all dentists in Northern Ireland who are registered to provide General Dental Services. Dentists' must be eligible for inclusion in a dental list because they have recently completed vocational training or have an exemption.

Some of the information that must be submitted when applying to join the list includes:

$\rightarrow$ Personal details

$\rightarrow$ Dental qualifications and proof of GDC registration

$\rightarrow$ Work history within dentistry

$\rightarrow$ Two clinical references, usually including one from the most recent place of work

$\rightarrow$ Information about the practice where the dentist will be working, including other dentists at the practice

$\rightarrow$ Proof of completion of vocational training or exemption

$\rightarrow$ Evidence of health clearance from the Occupational Health Service of the local Health and Social Care Trust

$\rightarrow$ Criminal records checks

$\rightarrow$ If English is not the first language, the results of an official English language test.

Attending a half-day New Start Information Session on responsibilities as a GDS dentist is also necessary, unless one has been attended within the last two years. If a dentist is already on a dental list and is getting an additional list number for work at another practice, they can complete the information session on-line.

\section{Corporate bodies and dental lists}

If a dentist is considering running their business as a dental body corporate (DBC) then they must take advice from a specialist dental accountant as there are important financial issues that need to be considered. HMRC have been carring out investigations into dentists who are running their business as a DBC. Please see BDA advice sheet Incorporation concerns in Northern Ireland and Scotland.

\section{Providing patient care}

The terms of service are contained in the GDS Regulations and describe the contractual responsibilities of dentists offering GDS dental care.

\section{Continuing care}

When an adult patient registers with a dentist for continuing care registration with a dentist lasts for 24 months.

\section{Capitation}

Patients aged under 18 years can be accepted for treatment under a capitation arrangement.

Contractor Principals are paid a fixed monthly fee for registered adult (Continuing Care) and child (Capitation) patients.

For HSC treatment a dentist can only charge the statutory patient charge listed in the Statement of Dental Remuneration (SDR). It includes a scale of fees listing more than 450 separate fees for item-of-service payments. The SDR also sets out some allowances, both practice based and individual allowances that can be claimed by dentists.

Further information of working in the GDS in Northern Ireland can be found on the BDA's website at: https://www.bda.org/nhs *

https://doi.org/10.1038/s41404-020-0305-z 